\title{
O ensino de termoquímica utilizando experimentação com material de baixo custo
}

\author{
Thermochemical teaching experimentation using low-cost materials \\ S. O. Martins ${ }^{1 *}$; J. R. Ferreira ${ }^{1}$; R. L. Monteiro ${ }^{2}$; R. F. Souza ${ }^{1}$ \\ ${ }^{l}$ Departamento de Ciências Naturais/Grupo de Pesquisa em Química, Ensino de Química e Meio Ambiente, Campus \\ XIX-Salvaterra, Universidade do Estado do Pará, 68860-000, Salvaterra-PA, Brasil \\ ${ }^{2}$ Instituto Federal de Educação, Ciência e Tecnologia do Pará, Instituto Federal de Educação, Ciência e Tecnologia \\ do Pará/TucuruíCampus Tucuruí. \\ *sabrina_martins238@hotmail.com
}

(Recebido em 08 de abril de 2016; aceito em 17 de abril de 2016)

\begin{abstract}
Este trabalho aborda a experimentação no ensino de termoquímica utilizando materiais de baixo custo. $\mathrm{O}$ trabalho aconteceu em uma escola localizada no município de Irituia, Pará, Brasil, contando com a participação de 58 alunos do $2^{\circ}$ ano do ensino médio. Utilizou-se como metodologia oficinas temáticas divida em três momentos pedagógicos: no primeiro momento foi trabalhado a problematização inicial, que sondou o conhecimento prévio dos alunos; no segundo momento trabalhou-se a organização do conhecimento, com o esclarecimento do assunto em questão; e no terceiro momento foi realizada a aplicação do conhecimento, quando os alunos realizaram práticas experimentais demonstrando domínio no assunto estudado. Após a concretização da prática, discutiram questões relevantes ao experimento com a intenção de obter os resultados de forma mais dinâmica e proveitosa no que diz respeito ao assunto abordado. Os resultados obtidos mostraram uma maior participação e interesse dos alunos pelo conteúdo em questão, confirmando assim a aprendizagem em relação ao assunto abordado. Percebeu-se ainda que houve uma evolução do pensamento dos estudantes antes e depois da aplicação da oficina temática, confirmando que a aplicação de tal prática pedagógica é de fundamental importância para o aprimoramento do ensino de química nas escolas públicas.
\end{abstract}

Palavras-chave: Experimentação, Recursos alternativos, Termoquímica

This work addresses the experimentation in teaching thermochemistry using low-cost materials. The work happened in a school in the municipality of Irituia, Pará, Brazil, with the participation of 58 students from $2^{\circ}$ year of high school. Used as thematic workshops methodology divided into three educational moments: the first moment has been initial questioning, where scanned if the prior knowledge of the pupils; in the second time worked if the organization of knowledge, with the clarification of the matter in question; and on the third time, the application of knowledge, when students performed experimental practices demonstrating subject matter studied domain. After the implementation of the practice, discussed issues relevant to the experiment with the intention of obtaining the results of more dynamic and fruitful as regards the subject. The results showed increased participation and interest of students for the content in question, thus confirming the learning in relation to the subject. It was noticed that there was an evolution of thought of students before and after the application of the thematic workshop, confirming that the application of such pedagogical practice is of fundamental importance for the improvement of chemistry teaching in public schools.

Keywords: Experimentation, Alternative resources, Thermochemistry 


\section{INTRODUÇÃO}

$\mathrm{Na}$ atualidade há necessidade de implementar novas estratégias didáticas referentes ao estudo da disciplina de química. E uma alternativa possível e viável é a utilização da experimentação aplicada ao cotidiano do aluno por meio de materiais alternativos e de baixo custo. O uso de material alternativo facilita a aplicação em sala de aula, uma vez que a maioria das escolas públicas não possui laboratórios que permitam a execução de aulas experimentais.

Aplicando a experimentação pretende-se alcançar a compreensão dos educandos de forma a simplificar o estudo dos conceitos de química, permitindo uma visualização dos fenômenos químicos por meio de experimentos simples. Segundo Guimarães [1], no ensino de ciências, deve-se considerar que as observações não são feitas embasadas em simples conceitos, no entanto, são adquiridas a partir de teorias que norteiam as observações. Dessa forma percebe-se a importância da teoria estar sempre vinculada à prática, pois possibilita ao aluno obter um conhecimento mais elevado do que está sendo ensinado.

Segundo Pereira [2] os professores relatam algumas dificuldades para abordar experimentação, como: número excessivo de alunos nas turmas, à carga horária reduzida e inadequação da infraestrutura. Contudo, é possível acrescentar aqui mais uma carência: a falta de clareza sobre o papel da experimentação na aprendizagem dos alunos.

Possivelmente não existe nada mais fascinante no aprendizado da química do que vê-la aplicada, e, diferentemente do que muitos professores possam pensar, não é necessária a utilização de sofisticados laboratórios, como também não são necessárias grandes verbas para a montagem de laboratórios didáticos [3].

Quando o estudante tem a possibilidade de acompanhar e explanar suas observações a respeito dos experimentos científicos, este possivelmente é capaz de criar soluções e discuti-las, facilitando a compreensão dos fenômenos químicos em sua volta, deste modo, alcançar o que se almeja com uma aula experimental que é fomentar no aluno o raciocínio lógico [4]. As atividades experimentais são consideradas por muitos professores como indispensável para $\mathrm{o}$ bom desenvolvimento do ensino [5], pois é um recurso que vem sendo adotada como prática pedagógica de transformação no ensino de química, proporcionando condições de questionamentos, organizações de pensamento e socialização de argumentos [6].

Neste contexto, as dificuldades apresentadas pelos alunos, bem como as encontradas pelo professor de repassar os conhecimentos, é indispensável que se adote a experimentação como recurso pedagógico, porém como se sabe, muitas escolas não possuem suporte adequado para o desenvolvimento deste tipo de aula. Dessa forma a adoção de práticas experimentais que utilizem material alternativo, é uma saída viável. Neste sentido, este trabalho discute a prática da investigação experimental de termoquímica utilizando material do cotidiano do aluno, fazendo que este possa ter um domínio acerca dos conteúdos deste tema.

\section{MATERIAL E MÉTODOS}

Esse trabalho foi realizado em uma escola estadual, localizada no município de Irituia, Pará, 58 alunos do segundo ano do ensino médio de duas turmas de turnos diferentes. A pesquisa foi executada nos meses de agosto e setembro de 2015. O tema escolhido para se trabalhar foi a termoquímica com ênfase nos processos endotérmicas e exotérmicas.

Nesta proposta de trabalho fez-se uso da oficina temática, aprimorada com os três momentos pedagógicos sugeridos por Muenchen; Delizoicov [7]. Os quais seguem descritos a seguir:

Problematização inicial: Nesse primeiro momento os estudantes são induzidos a apresentarem o que discorrem sobre o assunto, para que o professor tenha noção do que pensam [7]. A partir da exposição do tema a ser trabalhado, o educando é chamado a exibir seus conhecimentos a respeito do respectivo tema, fazendo assim com que ele queira buscar adquirir novos conhecimentos acerca do tema. Assim foi aplicado o questionário preliminar (Pergunta 1: 
Em sua opinião, onde a química está presente na sua vida? e Pergunta 2: Em sua opinião, o que termoquímica estuda?) no qual foi possível fazer uma investigação acerca dos conhecimentos prévios dos alunos relacionados a Termoquímica. Esta etapa foi executada por cada turma em aproximadamente vinte e três minutos.

Organização do conhecimento: Nesse segundo momento pedagógico o professor orienta o estudo dos conhecimentos necessários para a compreensão dos temas e da problematização inicial, visando uma compreensão das questões problematizadas dadas pelos educandos [8].

Nesta etapa foi ministrada uma micro aula com o intuito de dar uma compreensão melhor acerca do tema abordado, dando um maior esclarecimento sobre conceitos e definições de termos utilizados em termoquímica, além de tipos e classificações das reações termoquímicas. Esta etapa foi executada por cada turma em aproximadamente trinta minutos.

Aplicação do conhecimento: Esse momento destina-se a pôr em prática o saber do aluno, fazendo análise do conhecimento adquirido pelo estudante durante a tutoria do professor, como também ao conhecimento que este possui relacionado à temática abordada. Neste momento, trabalhou-se sistematicamente o conhecimento que o aluno acumulou com o tempo, para que o próprio possa compreender o problema proposto e associe o conhecimento adquirido com novas situações problemáticas [9].

Nesta etapa, executou-se diversos experimentos utilizando material encontrado facilmente no dia-a-dia. As turmas foram divididas em pequenos grupos, sendo que cada grupo tinha a responsabilidade de efetuar um experimento. A intenção dessa etapa era promover ao aluno uma visão prática do assunto facilitando dessa forma o seu aprendizado por ter uma associação da teoria com a prática. Durante os experimentos foram feitas perguntas simples sobre cada experiência visando explorar nos alunos o senso investigativo para que possam desta forma obter suas próprias explicações acerca das experiências.

Os experimentos realizados pelos alunos foram os seguintes: 1. Chama fria (material: água, acetona, fósforos e cilindro graduado); 2 . Água no balão (material: dois balões, vela, fósforos e água); 3. Sacarose (material: açúcar, colher, fósforos e vela); 4. Soda cáustica (material: soda cáustica, água, becker e espátula) e 5. Glicerina e permanganato (material: pílulas de permanganato, glicerina liquida e conta-gotas).

Para avaliar a aprendizagem, foi aplicado um questionário contendo perguntas relacionados aos experimentos realizados para a avaliação da relevância do trabalho.

\section{RESULTADOS E DISCUSSÃO}

Os dados obtidos através da aplicação do questionário aos participantes do projeto foram analisados e são apresentados a seguir.

Em relação à Pergunta 1 (Em sua opinião, onde a química está presente na sua vida?) do questionário preliminar, houve respostas variadas, onde os alunos apontaram que a química está presente nos alimentos, nos remédios, nos perfumes, nos sabonetes e na gasolina, assim percebe-se que houve uma associação significativa dos conceitos de química com o cotidiano. Abaixo segue uma transcrição literal de dois alunos relacionada a este questionamento.

"A química está presente a todo momento seja quando nos alimentamos, quando dormimos. Ex.: mudanças de temperatura". (Aluno A)

"Para mim está presente na cozinha, no remédio, produtos de beleza, nas ruas, nos mercados etc". (Aluno B)

Os alunos também foram questionados na Pergunta 2 sobre o que a termoquímica estuda, as respostas estão apresentadas na Figura 1. 


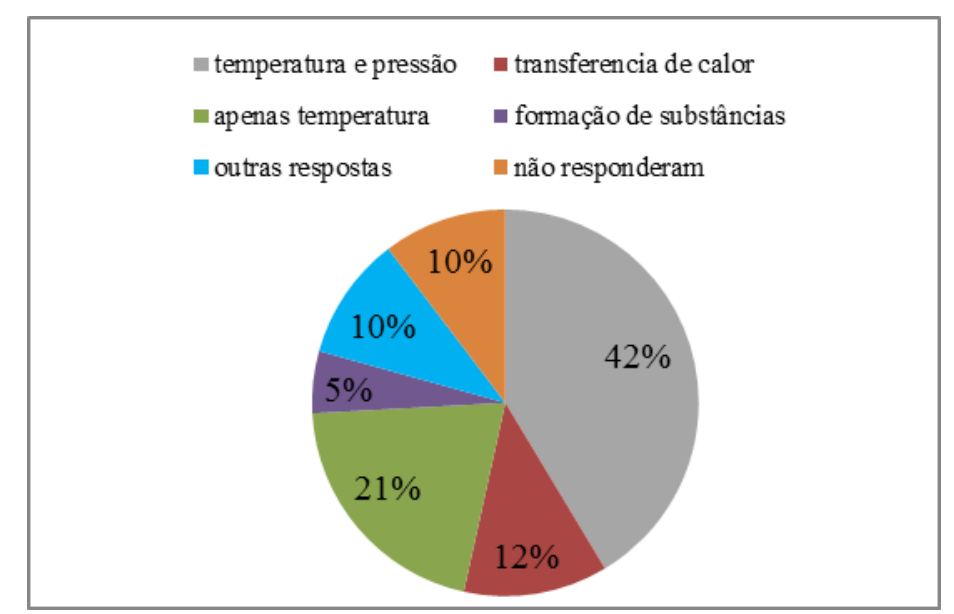

Figura 1. Respostas dos alunos sobre conceito de termoquímica

De acordo com os dados obtidos percebeu-se que cerca de $42 \%$ dos alunos responderam conceitos envolvendo temperatura e pressão; $21 \%$ conceitos envolvendo somente temperatura; e $12 \%$ responderam que termoquímica estuda as transferências de calor, o que mostra que muitos alunos ainda se confundem bastante em relação a conceitos básicos da química possivelmente devido à falta de visualização dos mesmos em seu dia a dia, pois entende-se que, se o aluno visualiza de forma concreta o que lhe está sendo ensinado facilita a assimilação do estudo em questão.

Segue abaixo algumas respostas dadas pelos alunos, transcritas literalmente:

"A termoquímica é uma temperatura química, estuda principalmente as reações obtidas através de combinações feitas entre alguns elementos como: $\mathrm{Fe}, \mathrm{Cl}, \mathrm{Br}$, etc.". (Aluno C)

"Estuda a temperatura em que ocorre a reação, pressão quando a reação envolve substancias gasosas estado de agregação de reagentes $e$ produtos, variedades alotrópica de reagentes e produtos, entre outros". (Aluno D)

Diante deste diagnostico realizou uma microaula e depois os experimentos. Na Figura 2 são apresentadas algumas imagens do momento da realização dos experimentos.

Em relação ao experimento chama fria, fez-se a seguinte pergunta: No experimento houve reação endotérmica ou exotérmica? Explique. Seguem as respostas dadas pelos alunos:

"Exotérmica porque observamos que ao colocarmos a mesma quantidade de álcool e água, percebemos que ocorre a liberação de calor, acrescentando o fósforo, e também a endotérmica porque a parte inferior contém água e a água não é inflamável". (Aluno E).

"O experimento é exotérmico porque a acetona é oxigênio e em tudo que tem oxigênio pega fogo". (Aluno F)

Outro questionamento feito: Por que ocorreu resfriamento na parte inferior e aquecimento na parte superior?

"Na parte inferior $\rightarrow$ ele absorveu todo calor, que estava envolvido na acetona, endotérmica. Na parte superior $\rightarrow$ ele liberou o calor, pois não havia nada para absorver o fogo, exotérmica". (Aluno G).

Em relação à terceira pergunta: o que explica o fato da parte inferior ter permanecido fria? Descreve-se abaixo uma fala de um aluno para o questionamento. 
"Endotérmica, a acetona não se mistura com a água e portanto a acetona fica em cima e a água fica em baixo é por isso que em baixo permanece fria". (Aluno $\mathrm{H}$ )

Pode-se observar que em todas as respostas ocorreu uma assimilação de conhecimento por parte do aluno em relação ao tema estudado

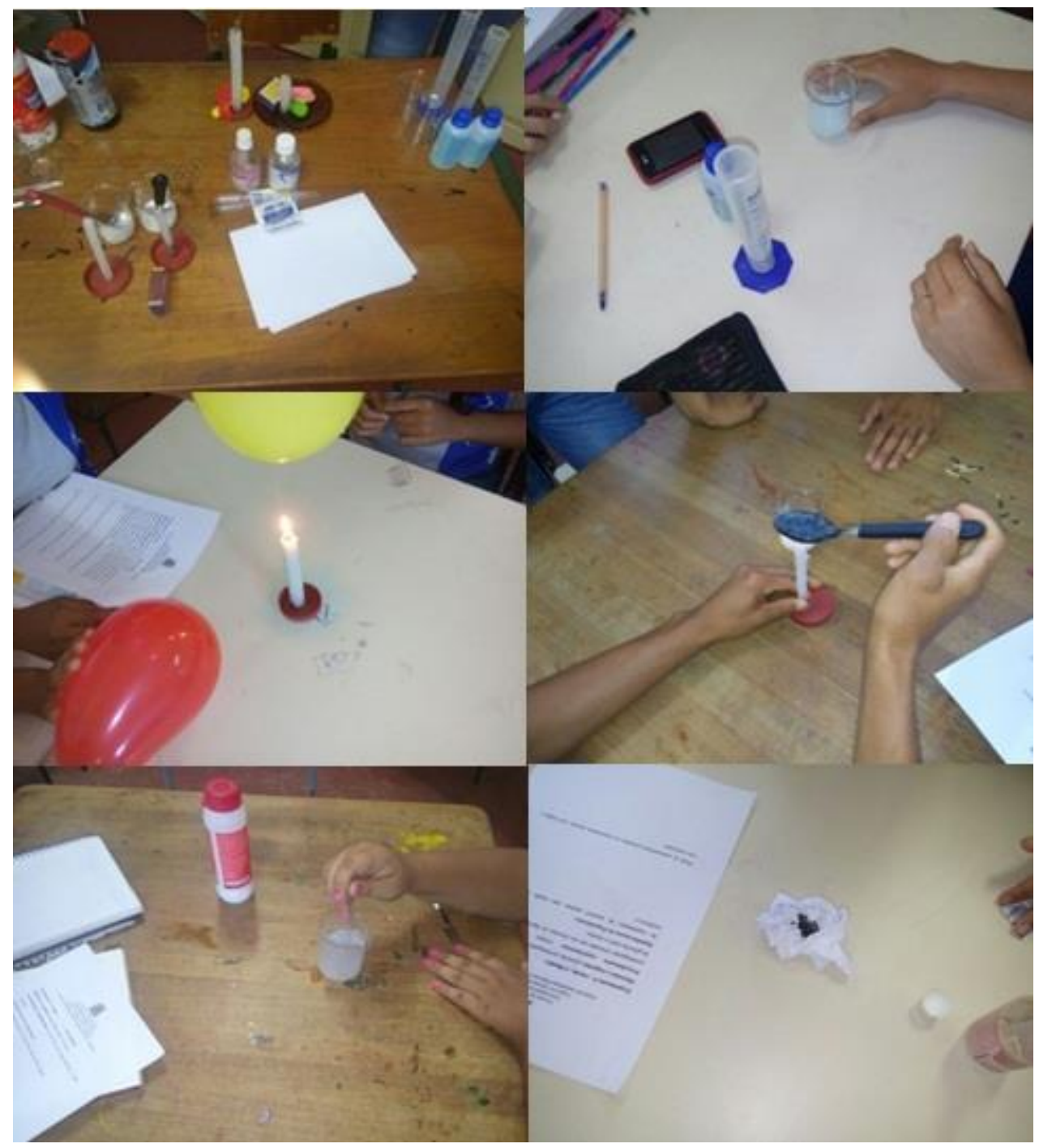

Figura 2- Imagens da realização dos experimentos

No Experimento sobre água no balão; todos os alunos participantes descreveram que ocorreu processo endotérmico, pois a água que estava dentro do balão absorveu o calor liberado pela chama da vela impedindo que o mesmo estourasse.

Em outro questionamento "por que o balão que continha apenas ar estourou mais rapidamente que o outro? segue abaixo trecho com resposta dada por um aluno acerca do experimento:

"O balão que continha apenas ar estourou mais rapidamente que o outro porque dentro do balão só continha ar, não absorvendo calor e sim liberando energia na forma de calor". (Aluno I) 
Em relação a outra pergunta relacionada ao experimento "Por que o balão que continha água demorou mais tempo para estourar?" segue abaixo trecho da fala de um aluno:

"O balão que continha água demorou mais tempo para estourar porque a água que estava dentro do balão absorveu o calor".

(Aluno J)

No experimento sobre a sacarose todos os alunos caracterizaram o experimento como uma reação endotérmica. E quanto a pergunta, "você acha que ocorreu no experimento um fenômeno físico ou químico", os mesmos alunos responderam que houve um fenômeno físico por não haver mudança na estrutura da molécula.

Como resposta para uma segunda pergunta "O que aconteceu com o açúcar?" observou-se a seguinte resposta dada por um aluno:

"Enquanto a colher estava quente o açúcar permaneceu líquido, $e$ logo em seguida da colher esfriar ele endureceu”. (Aluno K)

No experimento sobre soda cáustica, todos os alunos envolvidos observaram que quando foi adicionada soda cáustica à agua, o recipiente que continha os reagentes esquentou, evidenciando uma reação exotérmica com liberação de energia. Em resposta ao questionamento acerca do experimento "Houve perda ou absorção de calor? Como você observou isso?", menciona-se o seguinte trecho da fala de um aluno:

"Perda de calor, porque tinha vestígios de evaporação e pelo aquecimento do recipiente". (Aluno L)

No experimento sobre permanganato e glicerina todos alunos analisaram que se tratava de uma reação exotérmica. Em seguida, questionou-se "Quais as características presentes no experimento fizeram você chegar a essa conclusão?", segue abaixo uma resposta de um aluno:

"Liberação de energia na forma de calor e queima, por ser uma reação de combustão". (Aluno $\mathrm{M}$ )

Após a concretização da oficina temática, com base nas respostas dos questionários respondidas pelos alunos, percebeu-se que todos os alunos envolvidos no trabalho conseguiram entender o que a termoquímica estuda. E ambos caracterizaram as reações exotérmicas por liberarem energia na forma de calor e caracterizaram as reações endotérmicas por absorverem energia na forma de calor. Segue abaixo trechos da fala de alguns alunos com respostas ao que estuda a termoquímica:

"A termoquímica estuda as trocas de calor associadas às reações químicas ou a mudanças no estado de agregação das substâncias”. (Aluno N)

"A troca de calor das reações químicas, provocada pela troca de energia do meio externo com os reagentes". (Aluno $\mathrm{O}$ )

"A termoquímica estuda o calor das reações químicas". (Aluno P)

"A termoquímica é o que estuda calor nas experiências químicas". (Aluno Q)

Facilmente os alunos conseguiram associar os conteúdos trabalhados na oficina temática com seu o dia-a-dia, pois o material que foi utilizado para execução dos experimentos, é 
utilizado habitualmente em suas residências. Segundo Bueno; Kovaliczn [10] "os educadores devem promover atividades investigativas que tenham consonância com aspectos da vida dos alunos e que se constituam em problemas reais e desafiadores, realizando-se a verdadeira práxis, com o objetivo de ir além da observação direta das evidências e da manipulação dos materiais de laboratório".

Em vista da compreensão dos alunos aos conceitos do assunto abordado, tem-se na oficina temática uma eficaz ferramenta pedagógica para auxiliar os educadores e incentiva-los a investir nesta prática de ensino. "As manifestações dos alunos sobre o trabalho nas oficinas e suas participações nas mesmas representam um convite à continuidade dessa abordagem metodológica e incentivam sua divulgação para outros professores" [11].

Trabalhar oficinas temáticas com experimentos do próprio cotidiano dos alunos possibilitou uma assimilação dos fenômenos que os cercam com o ensino de química. No intuito de que se estabeleça uma aprendizagem significativa, é necessário analisar os fenômenos envolvidos refletindo os resultados, e para tanto deve haver uma integração, uma associação entre as aulas e as atividades experimentais, embora, pode resultar em uma sobrecarga de trabalho [10].

Após a execução das oficinas, pediu-se para os alunos participantes descrever exemplos de reações exotérmicas no dia-a-dia, os resultados estão mostrado na Figura 3.

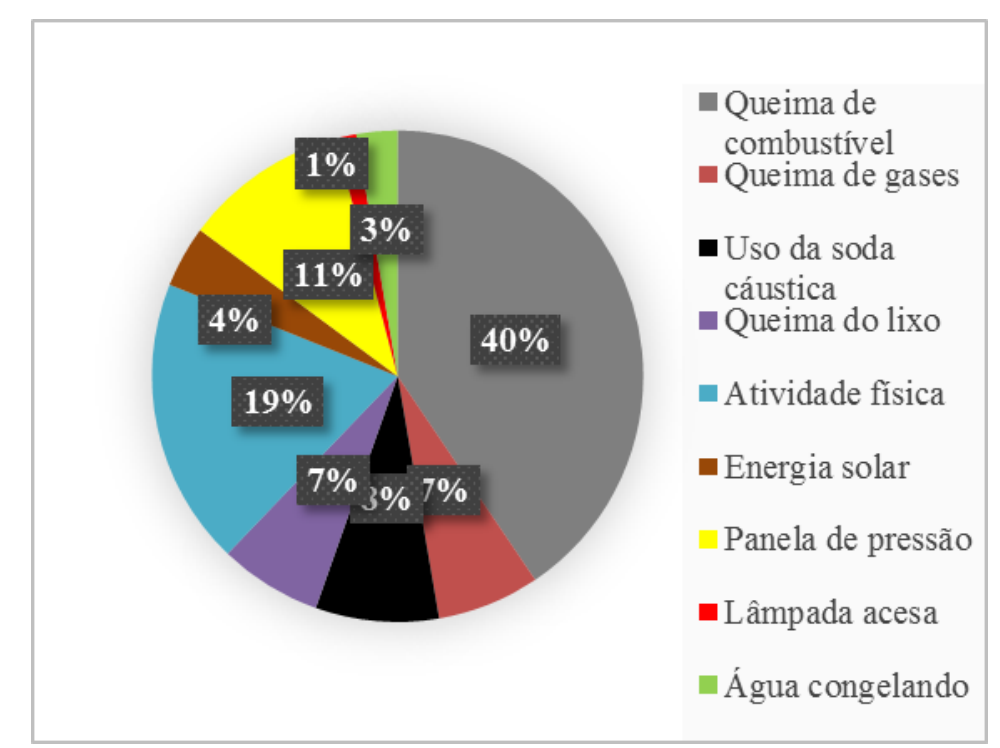

Figura 3. Exemplos de processos exotérmicos no dia - a -dia dos alunos

Considerando o gráfico com as devidas exemplificações de processos exotérmicos no cotidiano dos alunos, é notável que todos associaram as reações exotérmicas com uma perda (liberação) de energia. A maioria dos alunos, 40\%, citaram como exemplos de reações exotérmicas a queima de combustíveis, como o álcool, a gasolina, a parafina, entre outros. Enquanto que $19 \%$ exemplificaram a prática de atividades físicas, porque perdem energia quando jogam futebol, correm, nadam, caminham, etc. Outros alunos citaram como exemplos a queima de gases, o uso da soda cáustica, queima do lixo, a energia solar, a panela de pressão, a lâmpada acesa e a água congelando.

Em relação a exemplos de reações endotérmicas presenciadas pelos alunos em seu cotidiano, foi construído o gráfico a seguir (Figura 4) com base nas respostas dadas pelos alunos: 


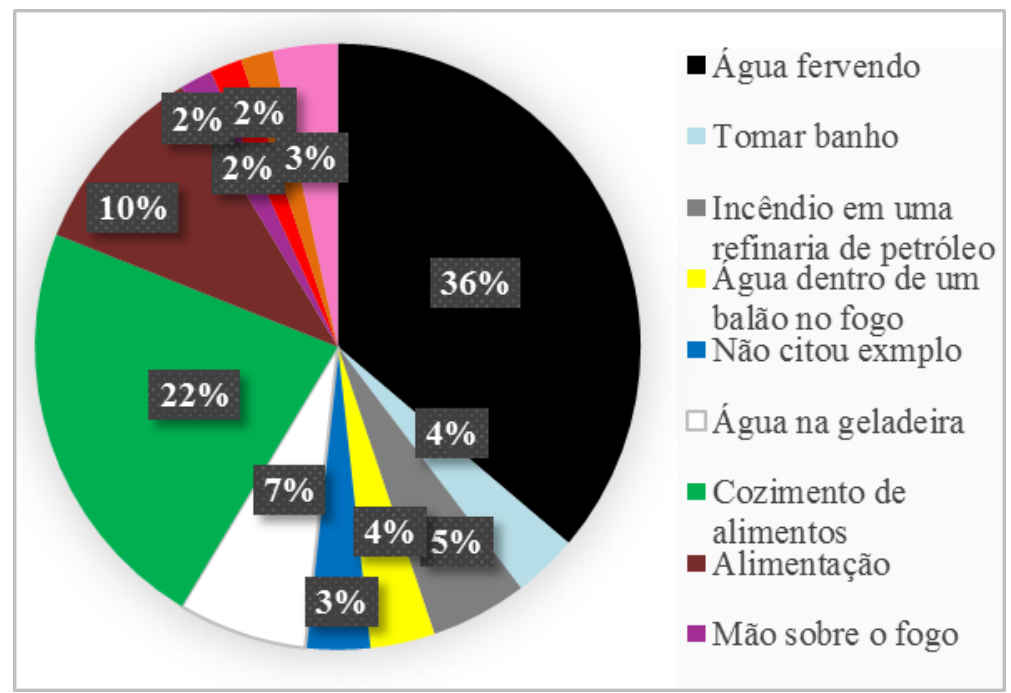

Figura 4. Exemplos de processos endotérmicos do cotidiano dos alunos

Notou-se que a mudança de estado físico da água, do estado líquido ao gasoso requer a absorção de energia na forma de calor para que esta possa alcançar fervura. Como exemplo de reação endotérmica presente no cotidiano dos alunos, $36 \%$ mencionaram a água fervendo; em seguida, $22 \%$ das respostas o exemplo foi o cozimento de alimentos; e $10 \%$ exemplificaram a alimentação como processo endotérmico; outros exemplos citados foram o ato de tomar banho, o incêndio em uma refinaria de petróleo, água dentro de um balão sobre o fogo, água na geladeira, mão sobre o fogo, queima do açúcar, entrar em uma sala resfriada, o uso do secador e da chapinha e alguns não citaram exemplos.

Pediu-se ainda que os alunos descrevessem quais assuntos de interesses por atividades experimentais, os resultados estão mostrados na Figura 5.

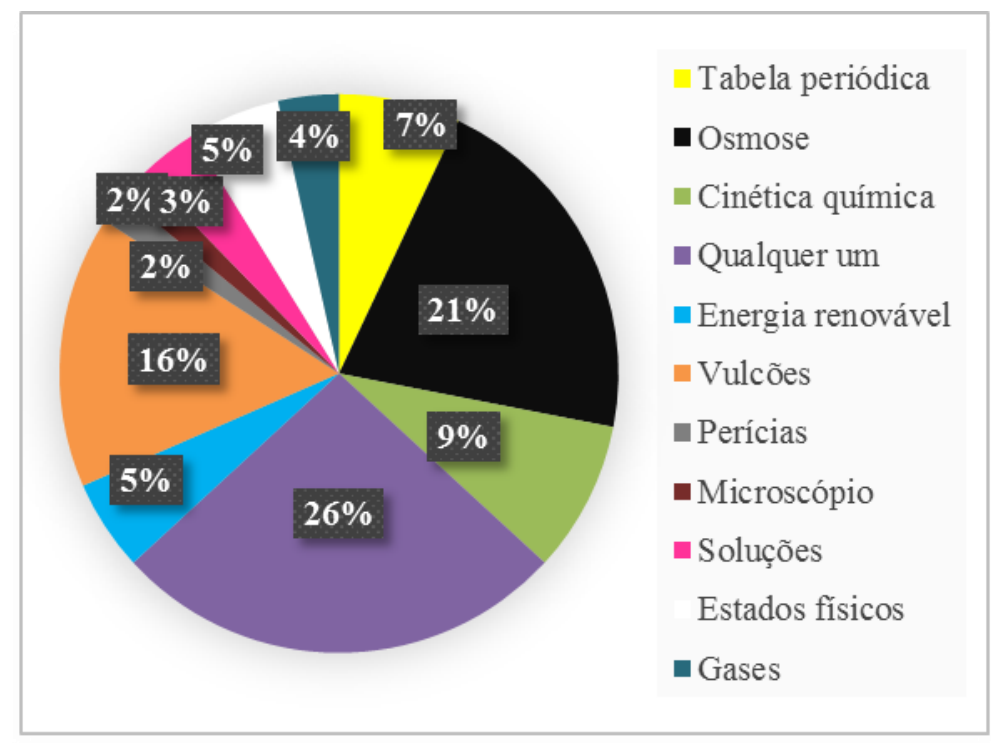

Figura 1. Outros assuntos de interesse dos alunos por atividades experimentais

A maioria dos alunos envolvidos na pesquisa demonstraram grande interesse por aulas práticas de química que envolva atividades experimentas. Foi analisado que a maior parte dos alunos, $26 \%$ desejam aulas com atividades experimentais manifestando interesse por qualquer assunto. Em seguida, 21\% ressaltaram o interesse por assuntos envolvendo osmose. Ainda foram de interesse dos alunos tabela periódica, cinética química, energia renovável, vulcões, perícias, microscópio, soluções, estados físicos e gases. Dessa forma cabe ao professor adotar a prática experimental como recurso pedagógico em suas aulas, explorando a curiosidade do 
aluno pela mesma, levando-os a enxergarem o estudo dos assuntos de química como um processo mais dinâmico e prazeroso.

Segundo Castro; Araújo [12] é necessário um trabalho que possa despertar a curiosidade dos alunos, vivenciando situações concretas através dos experimentos que são disponibilizados para os mesmos, ajudando no desenvolvimento das aulas e até mesmo aumentar o interesse por parte dos alunos, já que seriam utilizados materiais alternativos e de fácil acesso para todos.

\section{CONCLUSÃO}

Com o término da aplicação desse projeto, espera-se ter estimulado os educadores a adotarem práticas experimentais com recursos alternativos como ferramenta didática em suas aulas de química, visando facilitar a compreensão dos alunos diante dos assuntos abordados. Espera-se também que tais práticas tornem as aulas mais dinâmicas, que instiguem o aluno a se interessar mais pelo ensino de química, e agucem nos mesmos o processo investigativo de maneira que possam adquirir uma visão mais científica dos processos químicos que os cercam em seu dia a dia, tornando-os assim cidadãos críticos e atuantes da sociedade.

Com o uso da experimentação na sala de aula, os alunos assimilaram o conteúdo com maior facilidade, pois foi relacionado a teoria com a prática de modo investigativo.

Foi comprovada a eficácia da utilização de oficinas temáticas como ferramenta metodológica para as aulas de química, utilizando recursos alternativos, aplicado ao cotidiano do aluno.

\section{REFERÊNCIAS BIBLIOGRÁFICAS}

1. Guimarães CC. Experimentação no ensino de química: caminhos e descaminhos rumo à aprendizagem significativa. Química Nova na Escola 2009 ago;31(3):198-202.

2. Pereira BB. Experimentação no ensino de ciências e o papel do professor na construção do conhecimento. Cadernos da FUCAMP 2010; 9(11):1-9.

3. Marcondes MER, Silva, EL, Akahoshi LH, Souza FL, Carmo MP, Suart R, Martorano SAA, Torralbo

D. Oficinas temáticas no Ensino Público. 1. ed. São Paulo: FDE, 2007. v. 1. 108p.

4. Suart RC, Marcondes MER. As habilidades cognitivas manifestadas por alunos do ensino médio de química em uma atividade experimental investigativa. Revista Brasileira de Pesquisa em Educação em Ciências 2008;8(2):1-22.

5. Reginaldo CC, Sheid NJ, Güllich RIC. O ensino de ciências e a experimentação. In Anaped Sul: Seminário de Pesquisa em Educação da Região Sul, Giruá 2012, p. 1-13.

6. Baratieri SM, Basso, NRS, Borges RMR, João Filho BR. Opinião dos estudantes sobre a experimentação em química no ensino médio. Experiências em Ensino de Ciências 2008;3(3):19-31.

7. Muenchen C, Delizoicov D. Os três momentos pedagógicos e o contexto de produção do livro "Física". Ciência Educação 2014;20(3):617-638.

8. Zappe JÁ, Braibante MEF. Contribuições através da temática agrotóxicos para a aprendizagem de química e para a formação do estudante como cidadão. Revista Electrónica de Enseñanza de las Ciencias 2015;14(3):392-414.

9. Silva GS, Braibante MEF, Braibante HTS, Pazinato MS, Trevisans MC. Oficina temática: uma proposta metodológica para o ensino do modelo atômico de Bohr. Ciência Educação 2014;20(2):481-495. 10. Bueno RSM, Kovaliczn RA. O ensino de ciências e as dificuldades das atividades experimentais. Programa de Desenvolvimento Educacional - PDE. Curitiba: SEED/PR, 2011.

11. Marcondes MER. Proposições metodológicas para o ensino de química: oficinas temáticas para a aprendizagem da ciência e o desenvolvimento da cidadania. Em Extensão 2008;7:67-77.

12. Castro CL, Araújo SCM. Uma proposta de experimentos com materiais alternativos a partir da análise do Livro didático. ENEQ, Salvador, BA, 2012. 